\title{
Dataset Paper \\ In Vivo Antioxidant Activity of Topical Cream of Cassia tora L. Leaves Extract
}

\author{
V. Gupta, ${ }^{1}$ D. S. Rathore, ${ }^{2}$ Niraj P. Kansara, ${ }^{3}$ and A. M. Badiger ${ }^{4}$ \\ ${ }^{1}$ Department of Pharmacology, Faculty of Pharmaceutical Sciences, Jodhpur National University, Jodhpur 342001, Rajasthan, India \\ ${ }^{2}$ Department of Pharmaceutics, Rajasthan Pharmacy College, Jaipur 303006, Rajasthan, India \\ ${ }^{3}$ Department of Pharmacology, School of Pharmaceutical Sciences, Jaipur National University, Jaipur 302025, Rajasthan, India \\ ${ }^{4}$ Department of Chemistry, Shree Dhanvantary Pharmaceutical Analysis and Research Centre, Kim, Surat 394110, Gujarat, India
}

Correspondence should be addressed to Niraj P. Kansara; nick_14886@yahoo.com

Received 5 April 2012; Accepted 29 April 2012

Academic Editors: R. Garay and T. Posser

Copyright (c) 2013 V. Gupta et al. This is an open access article distributed under the Creative Commons Attribution License, which permits unrestricted use, distribution, and reproduction in any medium, provided the original work is properly cited.

\begin{abstract}
Objective. The aim of study was to determine the in vivo antioxidant activity of newly formulated $\mathrm{O} / \mathrm{W}$ cream of methanolic extract of Cassia tora L. leaves. Methods. Oil in water (O/W) creams $(0.05 \%, 0.1 \%$, and $0.2 \%)$, cream base, methanolic extract of C. tora L. leaves (CTM), and standard (0.05\% tretinoin cream) were screened for in vivo antioxidant activity. The ultraviolet- (UV-) Binduced rats were treated with different standard, O/W creams, cream base, and methanolic extract of Cassia tora L. leaves (CTM). The parameters like lipid peroxidation (LPO), reduced glutathione (GSH), superoxide dismutase (SOD), and catalase (CAT) levels were assessed. Results. The result of acute dermal toxicity shows that the creams were safe up to $2000 \mathrm{mg} / \mathrm{kg}$ (topically). Exposure of ultraviolet light of medium wave (UV-B light) decreased the level of GSH, CAT, and SOD and increased the LPO level. Concluding Remarks. We conclude that topical O/W creams of C. tora L. prevent the oxidative stress induced in rats by exposure to UV-B light by virtue of its in vivo antioxidant property, and these findings help to understand the mechanism of the antipsoriatic activity of $\mathrm{O} / \mathrm{W}$ creams of $\mathrm{C}$. tora $\mathrm{L}$. in UV-B-induced psoriasis in the rat.
\end{abstract}

\section{Introduction}

N. P. Kansara found a potent antipsoriatic activity of $\mathrm{O} / \mathrm{W}$ creams of Cassia tora L. in ultraviolet- (UV) -B-induced psoriasis in the rat. Aerobic organisms produce reactive oxygen species during normal respiration and inflammatory conditions. Exercise can create an imbalance between oxidant and antioxidant levels, a situation known as oxidative stress. Indeed, oxidative stress resulting from acute exercise in unadapted and adapted subjects has been proposed to damage enzymes, protein receptors, lipid membranes, and DNA [1].The plant C. tora L. (Caesalpiniaceae) is traditionally claimed to be useful in the treatment of psoriasis and other skin diseases $[2,3]$. C. tora L. leaves enriched in glycosides and also containing aloe-emodin may be beneficial for the skin diseases [4]. C. tora L. has been reported to possess a significant antioxidant activity in in vitro activity by using DPPH
(2,2' -diphenyl-1-picryhydrazyl) method [5]. In these antioxidant assays, the volatile oil from $C$. tora L. demonstrated $2,2^{\prime}$-diphenyl-1-picryhydrazyl radical-scavenging activity in the concentration range from 20 to $500 \mu \mathrm{g} / \mathrm{mL}$, with the $50 \%$ inhibitory concentration $\left(\mathrm{IC}_{50}\right)$ value at $137 \mu \mathrm{g} / \mathrm{mL}$; it also showed a significant inhibitory effect against hydroxyl radicals with an $\mathrm{IC}_{50}$ value of $67 \mu \mathrm{g} / \mathrm{mL}$, lower than that of quercetin $\left(\mathrm{IC}_{50}=8.15 \mu \mathrm{g} / \mathrm{mL}\right)$, but superior to that of 4 terpineol $\left(\mathrm{IC}_{50}=87.5 \mu \mathrm{g} / \mathrm{mL}\right)$. We had used UV-B ray as a damage inductor because it causes skin to burn and directly damages DNA by interfering with its replication cycle [6]. And excessive exposure to UV-A radiation has its risks, which may cause premature aging, including wrinkles, sunspots, and loss of skin elasticity [7]. Hence, it was proposed to evaluate the efficacy of $\mathrm{O} / \mathrm{W}$ creams and methanolic extract of C. tora L. leaves (CTM) to prevent the UV-B-induced oxidative stress. 


\section{Methodology}

Standard (tretinoin: $0.05 \%$ ) cream was obtained from Ethnor pharma (A Johnson \& Johnson Div.), Mumbai, Maharashtra, India. Diethyl ether was obtained from Rankem, India. Other ingredients such as light liquid paraffin (Astron), cetostearyl alcohol (Chemdyes), propylene glycol (Nomex), white soft paraffin (Nomex), butyl hydroxyl toluene (Rankem), benzyl alcohol (Chemdyes), disodium EDTA (Rankem), isopropyl myristate (FD, Fine Chemicals), and dibasic potassium phosphate (Rankem) were used to prepare O/W creams. Pyrogallol and hydrogen peroxide were obtained from SD Fine Chemicals Ltd., India. Thiobarbituric acid (TBA), trichloroacetic acid (TCA), 5,5'-dithiobis (2-nitrobenzoic acid) (DTNB), phosphate buffer, and Tris buffer were obtained from Sigma, USA. All reagents used were of analytical grade.

Leaves of C. tora L. (Cesalpinaceae) were collected from Dabhoi, Vadodara, Gujarat [8].

The methanolic extract was prepared by cold maceration method [8].

Formulation development was as follows. The extract was heated up to $70 \pm 5^{\circ} \mathrm{C}$. Aqueous phase consisting of water (q.s) was heated to the same temperature and then were added disodium EDTA (0.01\%), butyl hydroxyl toluene $(0.001 \%)$, and dibasic potassium phosphate $(0.2 \%)$ in it. Then CTM $(0.05 \%, 0.1 \%$, and $0.2 \%)$ was mixed in benzyl alcohol (1\%) and added in it. Then, oily phase was added to the aqueous phase with continuous stirring at slow speed for 1 hour and slowly decreased the temperature and meanwhile was added isopropyl myristate $(4 \%)$ in the mixtures of both phases. Allowed to cool at room temperature. Oily phase was consisted of light liquid paraffin (8\%), cetostearyl alcohol (10\%), propylene glycol (5\%), and white soft paraffin wax (12\%). The prepared creams were transferred into wide mouth containers and stored in cool place. Base was also prepared by the same previous method and with same ingredients but without CTM.

Evaluation of $\mathrm{O} / \mathrm{W}$ creams was as follows.

Physical evaluation was done as per Singhal \& Kansara, International Scholarly Research Network $[8,9]$.

Sensitivity test, irritastion test, and grittiness were performed as per Singhal \& Kansara, International Scholarly Research Network [8].

Stability studies were done according to Singhal \& Kansara, International Scholarly Research Network $[8,10]$.

Adult Wistar male rats (weight: approximately $300 \mathrm{~g}$; age: 4-6 months) were used for the experiments. Animals were kept in the Shree Dhanvantary Pharmaceutical Analysis and Research Centre, Kim, Surat. After approval from the Institutional Animal Ethical Committee (Reg. no.1103/abc/07/cpcsea), rats were housed in polypropylene cages as 3 animals per cage with rice husk as the bedding material for $12 \mathrm{~h}$ light-dark cycle, at temperature of $22 \pm$ $02^{\circ} \mathrm{C}$, and humidity 30-70\%. Rat pellet feed (Pranav agro Ltd.) and pure drinking water were supplied ad libitum. The animals were acclimatized to the laboratory conditions for a minimum period of seven days prior to commencement of treatment.
The acute dermal toxicity test was performed according to Singhal \& Kansara, International Scholarly Research Network [8].

In vivo antioxidant studies were as follows. For the assessment of different formulations and crude extract on UV$\mathrm{B}$-induced oxidative stress in rats, the animals were treated with respective doses (topically, single dose) of different concentrations of $\mathrm{O} / \mathrm{W}$ creams (Test $1,0.05 \%$; Test 2, $0.1 \%$; and Test 3, 0.2\%), standard (tretinoin: $0.05 \%$ ), cream base, and crude extract during whole treatment. The animals were divided into seven groups as follows:

Group 1: Positive control received UV-B light,

Group 2: UV-B + standard,

Group 3: UV-B + Test 1,

Group 4: UV-B + Test 2,

Group 5: UV-B + Test 3,

Group 6: UV-B + cream base,

Group 7: UV-B + extract.

The procedure was as follows. Wistar rats were selected and divided into seven groups. Then hair of the dorsal skin was carefully shaved. Then test creams were applied topically on the dorsal part of the skin whichever was exposed to radiation. An area $(1.5-2.5 \mathrm{~cm})$ on one side of the flank was irradiated for $15 \mathrm{~min}\left(1.5 \mathrm{~J} / \mathrm{cm}^{2}\right)$ at a vertical distance of $20 \mathrm{~cm}$ with UV-B lamps. Then following parameters were assessed in the blood which was withdrawn from the retroorbital plexus at the end of last treatment in the UV-Binduced psoriasis.

To evaluate lipid peroxidation (LPO), $2 \mathrm{~mL}$ of $5 \%$ suspension of separated RBC in $0.1 \mathrm{M}$ phosphate-buffered saline and $2 \mathrm{~mL}$ of $28 \%$ trichloroacetic acid were taken in test tube and centrifuged. Then supernatant was separated in another test tube. Then $4 \mathrm{~mL}$ of supernatant was taken in test tube and $1 \mathrm{~mL}$ of $1 \%$ thiobarbituric acid was added in it. Then it was heated in boiling water for 60 minutes and cooled immediately. The absorbance was measured in UV spectrophotometer (Schimadzu 1601, Japan) at $532 \mathrm{~nm}$ [1113].

Superoxide dismutase (SOD) was evaluated as follows. The erythrocyte lysate was prepared from the 5\% RBC suspension of the blood. Then $50 \mu \mathrm{L}$ of the erythrocyte lysate was taken in test tube and then $75 \mathrm{mM}$ of Tris- $\mathrm{HCl}$ buffer $(\mathrm{pH}$ 8.2), $30 \mathrm{mM}$ EDTA, and $2 \mathrm{mM}$ of pyrogallol were added in it. Then absorbance was recorded at $420 \mathrm{~nm}$ for $3 \mathrm{~min}$ by UV spectrophotometer (Schimadzu 1601, Japan) [11-13].

Catalase (CAT) activity was determined in erythrocyte lysate using Aebi's method with some modifications. $50 \mu \mathrm{L}$ of the lysate was added into a cuvette containing $2 \mathrm{~mL}$ of phosphate buffer ( $\mathrm{pH} 7.0$ ) and $1 \mathrm{~mL}$ of $30 \mathrm{mM} \mathrm{H}_{2} \mathrm{O}_{2}$. Catalase activity was measured at $240 \mathrm{~nm}$ for $1 \mathrm{~min}$ using UV spectrophotometer (Schimadzu 1601, Japan) [11-13].

Reduced glutathione (GSH) was evaluated as follows. Blood glutathione was measured by addition of $0.2 \mathrm{~mL}$ of whole blood in $1.8 \mathrm{~mL}$ distilled water followed by $3.0 \mathrm{~mL}$ of precipitating mixture of $1.67 \mathrm{~g}$ metaphosphoric acid, $0.2 \mathrm{~g}$ EDTA, and $30 \mathrm{~g} \mathrm{NaCl}$ to make $100 \mathrm{~mL}$ of solution. It was 

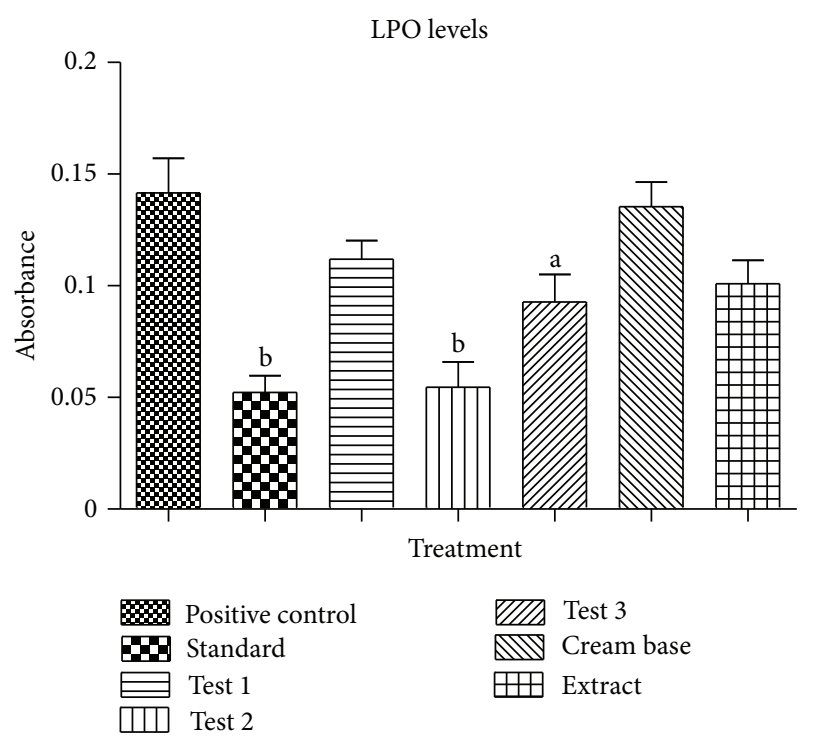

FIGURE 1: Effect of different formulations on blood LPO in UV-Binduced psoriatic rat. ${ }^{\mathrm{a}} P<0.05 ;{ }^{\mathrm{b}} P<0.001$, compared to positive control group.

centrifuged at $5000 \times \mathrm{g}$ for $5 \mathrm{~min}$ and $1 \mathrm{~mL}$ of the filtrate was added to $1.5 \mathrm{~mL}$ of the phosphate solution, followed by the addition of $0.5 \mathrm{~mL}$ of DTNB reagent. The optical density was measured at $412 \mathrm{~nm}$ using UV spectrophotometer (Schimadzu 1601, Japan) [11-13].

Statistical analysis was as follows. All the experimental results were expressed as mean \pm SEM. For statistical comparisons, explorative probabilities were obtained by the oneway ANOVA followed by Dunnett's multiple comparison tests using GraphPad Prism 5 (GraphPad software, Inc.). The intergroup difference was considered significant when $P<$ 0.05 .

For the evaluation of creams, three different concentrations of $\mathrm{O} / \mathrm{W}$ creams (Test 1, 0.05\%; Test 2, 0.1\%; and Test $3-0.2 \%)$ were prepared to evaluate antipsoriatic activity. Physical evaluation revealed that creams were having light green colour, characteristic odour, semisolid in nature, and $\mathrm{pH}$ ranges from 6.5 to 7 . They passed the sensitivity test and irritation test. During stability study, no phase separation and liquefaction were observed.

The acute dermal toxicity test of creams was determined according to the OECD 402 (Organization for Economic Corporation and Development). The creams were safe up to the dose of $2000 \mathrm{mg} / \mathrm{kg}$. There were no changes in fur, eyes, and behavior of treated animals as well as no toxic reactions were determined. And from results suitable doses $(250 \mathrm{mg}$ $(0.05 \%), 500 \mathrm{mg}(0.1 \%)$, and $1000 \mathrm{mg}(0.2 \%))$ were chosen for each activity in each cream for further in vivo studies.

\section{Dataset Description}

The dataset associated with this Dataset Paper consists of 4 items which are described as follows.

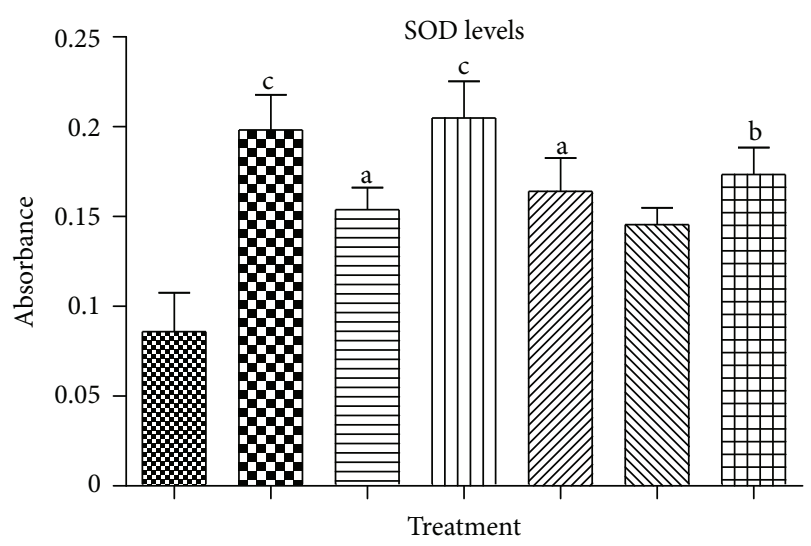

\begin{tabular}{ll} 
\% Positive control & WIA Test 3 \\
Standard & MII Cream base \\
Test 1 & Ex Extract \\
\hline Test 2 &
\end{tabular}

FIGURE 2: Effect of different formulations on blood SOD in UV-Binduced psoriatic rat. ${ }^{\mathrm{a}} \mathrm{P}<0.05 ;{ }^{\mathrm{b}} \mathrm{P}<0.01 ;{ }^{\mathrm{c}} \mathrm{P}<0.001$, compared to positive control group.

Dataset Item 1 (Table). Effect of different formulations on blood LPO in UV-B-induced psoriatic rat. In the table, each value represents Mean \pm SEM, $n=6$; "a" indicates $P<$ 0.05 ; and " $\mathrm{b}$ " indicates $P<0.001$, compared to positive control group. Evaluation of in vivo antioxidant activity was as follows. There was a dose-dependent inhibition of in vivo lipid peroxidation by the different formulations (Test 1 , $250 \mathrm{mg}$; Test 2, $500 \mathrm{mg}$; and Test 3, $1000 \mathrm{mg}$ ) of methanolic extract of leaves of C. tora L. cream. Standard (tretinoin: $0.25 \mathrm{mg}$ cream) showed $63.18 \%$ inhibition whereas UV-B + Test 2 had 61.48\% inhibition and UV-B + Test 3 had 34.56\% inhibition, which was statistically significant (Figure 1).

\section{Column 1: Group Number \\ Column 2: Topical Treatment \\ Column 3: Mean \pm SEM Inhibition (\%)}

Dataset Item 2 (Table). Effect of different formulations on blood SOD in UV-B-induced psoriatic rat. In the table, each value represents Mean \pm SEM, $n=6$; "a" indicates $P<0.05$; "b" indicates $P<0.01$; and "c" indicates $P<0.001$, compared to positive control group. There was a marked depletion of SOD levels in positive control group. Treatment with standard (tretinoin: $0.25 \mathrm{mg}$ cream) prevented the depletion of SOD to extend of $130.73 \%$. Percentage increase in SOD level in different formulations as well as extract group was found to be $79.04 \%$ (UV-B + Test 1), 138.53\% (UV-B + Test 2), $91.04 \%$ (UV-B + Test 3), and 101.86\% (UV-B + extract), respectively, which were statistically significant (Figure 2).

Column 1: Group Number

Column 2: Topical Treatment

Column 3: Mean \pm SEM Increase (\%) 
Dataset Item 3 (Table). Effect of different formulations on blood catalase in UV-B-induced psoriatic rat. In the table, each value represents Mean \pm SEM, $n=6$; "a" indicates $P<0.05$; and " $\mathrm{b}$ " indicates $P<0.001$, compared to positive control group. There was a marked depletion of catalase level in positive control group. Treatment with standard (tretinoin: $0.25 \mathrm{mg}$ cream) had increased the level up to $145.17 \%$. Treatment with different formulations and extract group were found to be $130.83 \%{ }^{\mathrm{b}}$ (UV-B + Test 2), $76.76 \%$ (UV-B + Test 3), and $124.71 \%{ }^{\mathrm{b}}$ (UV-B + extract), respectively, which were statistically significant (Figure 3 ).

\section{Column 1: Group Number}

Column 2: Topical Treatment

Column 3: Mean \pm SEM Increase (\%)

Dataset Item 4 (Table). Effect of different formulations on blood GSH in UV-B-induced psoriatic rat. In the table, each value represents Mean \pm SEM, $n=6$; and "b" indicates $P<0.001$, compared to positive control group. There was a marked depletion of GSH level in positive control group. Treatment with standard (tretinoin: $0.25 \mathrm{mg}$ cream) has increased the level up to $94.45 \%$. Treatment with different formulations and extract group were found to be $56.42 \%$ (UV-B + Test 1), 89.46\% (UV-B + Test 2), 71.77\% (UV-B + Test 3), and 64.54\% (UV-B + extract), respectively, which were statistically significant (Figure 4 ).

Column 1: Group Number

Column 2: Topical Treatment

Column 3: Mean \pm SEM Increase (\%)

\section{Concluding Remarks}

Free radical stress leads to tissue injury and progression of disease such as cancer, aging, ischemia, liver injury, arthritis, and Parkinson's syndrome. Safer antioxidants suitable for long-term use are needed to prevent or stop the progression of free radical-mediated disorders [14]. Many plants possess antioxidant ingredients that provided efficacy by additive or synergistic activities. Some studies have shown that a number of plant products including polyphenolic substances and herb extracts exert potent antioxidant action. Some traditional natural antioxidants are already exploited commercially either as antioxidant additives or as nutritional supplements [15].

Superoxide dismutase mainly acts by quenching of superoxide, catalase by catalyzing the decomposition of hydrogen peroxide to water and oxygen. Glutathione reductase is a good scavenger of many free radicals like $\mathrm{O}_{2}{ }^{-}, \mathrm{HO}$, and various lipid hydroperoxides and may help to detoxify many inhaled oxidizing air pollutants like ozone, $\mathrm{NO}_{2}$, and free radicals in cigarette smoke in the respiratory tract [16]. Exposure of UV-B light leads to cellular changes, DNA damage, and also skin damage [17].

The present study has shown that exposure of UV-B light for $15 \mathrm{~min}$ not only damaged the skin but also produced
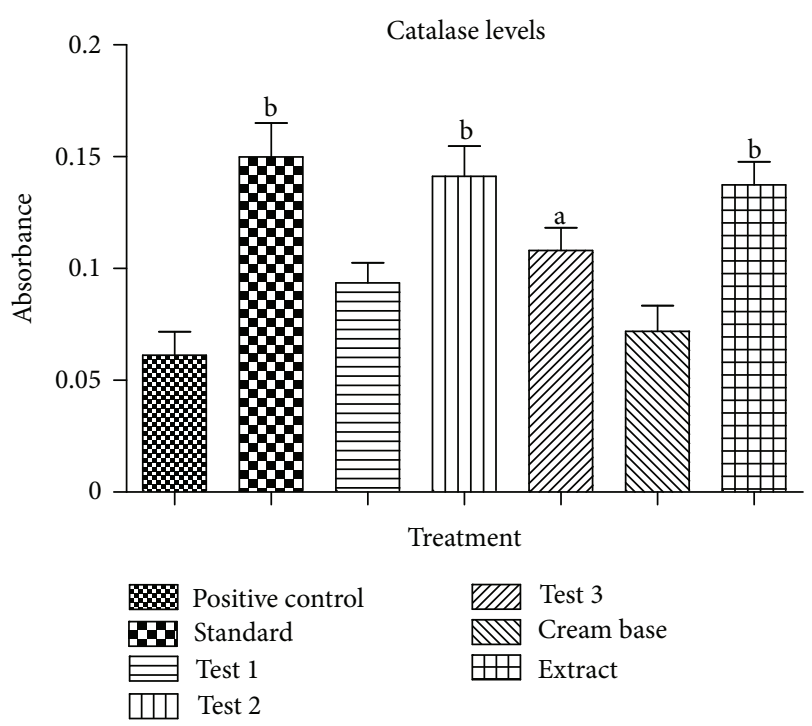

FIGURE 3: Effect of different formulations on blood catalase in UVB-induced psoriatic rat. ${ }^{\mathrm{a}} P<0.05$; ${ }^{\mathrm{b}} \mathrm{P}<0.001$, compared to positive control group.

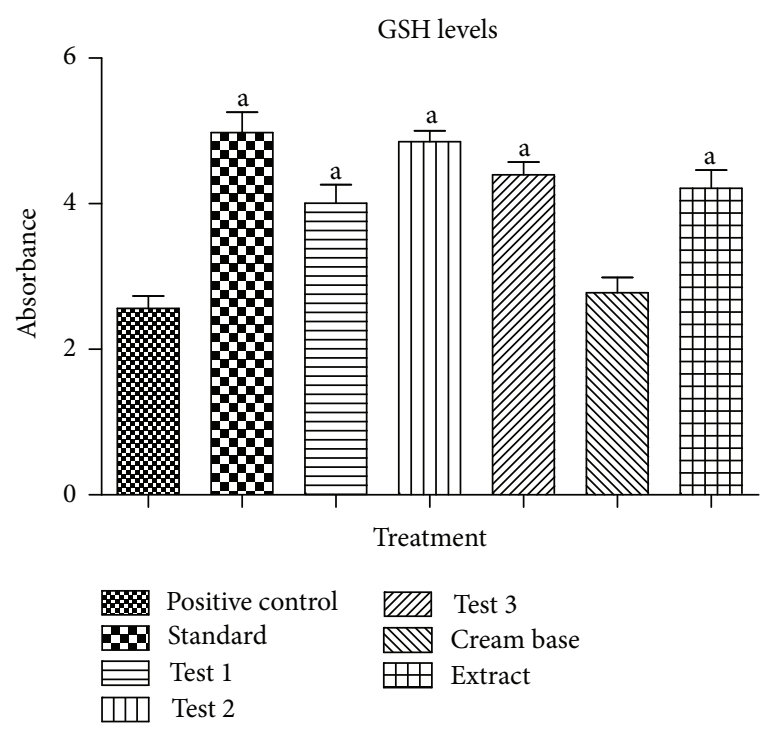

FIGURE 4: Effect of different formulations on blood GSH in UVB-induced psoriatic rat. ${ }^{\mathrm{a}} \mathrm{P}<0.001$, compared to positive control group.

oxidative stress in rats. The literature has documented free radical generation and DNA damage occurs during the exposure of UV-B light [17]. UV exposure, particularly UV$B$ rays, causes the generation of free radicals and related reactive oxygen species, which contribute to carcinogenesis by directly damaging cellular macromolecules, including DNA [18]. The level of the markers of oxidative stress, observed in UV-B-induced rats, substantiates the possibility of extensive generation of free radicals. It is further observed that application of different concentrations of $\mathrm{O} / \mathrm{W}$ creams and CTM prevented the UV-B-induced oxidative stress parameters, and the effect was comparable to that of standard. 
Hence, the observed in vivo antioxidant activity of different concentrations of $\mathrm{O} / \mathrm{W}$ creams and CTM was substantiation of its earlier reported activity in in vitro studies [5].

Antioxidants act as free radical scavengers that destroy single oxygen molecules (free radicals) in the body, thereby protecting against oxidative damage of cells. SOD, catalase (CAT), GSH, and so forth are the well-known enzymes present in plasma which act as antioxidants by transforming reactive oxygen species and reactive nitrogen species into the stable compounds and involved in a scavenging of the excessive free radicals. The restoration of blood SOD, CAT, and GSH levels by the treatment with test creams is indicating that the inbuilt protective mechanism is being restored.

\section{Dataset Availability}

The dataset associated with this Dataset Paper is dedicated to the public domain using the CC0 waiver and is available at http://dx.doi.org/10.7167/2013/243949/dataset.

\section{References}

[1] C. Leeuwenburgh and J. W. Heinecke, "Oxidative stress and antioxidants in exercise," Current Medicinal Chemistry, vol. 8, no. 7, pp. 829-838, 2001.

[2] C. P. Khare, Indian Medicinal Plants: An Illustrated Dictionary, Springer, Berlin, Germany, 2007.

[3] J. A. Duke, Handbook of Medicinal Herbs, CRC Press, Florida, Fla, USA, 2nd edition, 2002.

[4] T. K. Maity, S. C. Mandal, T. Bhakta, M. Pal, and B. P. Saha, "Metabolism of 1,8-dihydroxy 3-hydroxy methyl anthraquinone (Aloe-emodin) isolated from the leaves of Cassia tora in albino rats," Phytotherapy Research, vol. 15, no. 5, pp. 459-460, 2001.

[5] Y. Zhang, D. Wei, S. Guo, X. Zhang, M. Wang, and F. Chen, "Chemical components and antioxidant activity of the volatile oil from Cassia tora L. seed prepared by supercritical fluid extraction," Journal of Food Lipids, vol. 14, no. 4, pp. 411-423, 2007.

[6] Environmental Protection Agency, RadTown USA, UV Tanning Equipment.

[7] G. J. Fisher, Z. Wang, S. C. Datta, J. Varani, S. Kang, and J. J. Voorhees, "Pathophysiology of premature skin aging induced by ultraviolet light," The New England Journal of Medicine, vol. 337, no. 20, pp. 1419-1428, 1997.

[8] M. Singhal and N. Kansara, "Cassia tora Linn creamInhibits ultraviolet-B-induced psoriasis in rats," ISRN Dermatology, vol. 2012, Article ID 346510, 6 pages, 2012.

[9] S. Saraf and S. Saraf, Cosmetics a Practical Manual, PharmaMed Press, 2nd edition, 2009.

[10] ICH Guidelines, "Stability testing of Now Drug Substances and Products," 1993.

[11] H. Nakaguma, T. Kambara, and T. Yamamoto, "Rat ultraviolet ray $\mathrm{B}$ photodermatitis: an experimental model of psoriasis vulgaris," International Journal of Experimental Pathology, vol. 76, no. 1, pp. 65-73, 1995.

[12] H. G. Vogel, Drug Discovery and Evaluation-Pharmacological Assays, Springer, Berlin, Germany, 2nd edition, 2002.

[13] A. A. Joharapurkar, S. P. Zambad, M. M. Wanjari, and S. N. Umathe, "In vivo evaluation of antioxidant activity of alcoholic extract of Rubia cordifolia Linn. and its influence on ethanolinduced immunosuppression," Indian Journal of Pharmacology, vol. 35, no. 4, pp. 232-236, 2003.

[14] M. Sumanth and A. C. Rana, "In vivo antioxidant activity of hydroalcoholic extract of Taraxacum officinale roots in rats," Indian Journal of Pharmacology, vol. 38, no. 1, pp. 54-55, 2006.

[15] A. V. Krishnaraju, C. V. Rao, T. V. N. Rao, K. N. Reddy, and G. Trimurtulu, "In vitro and in vivo antioxidant activity of Aphanamixis polystachya bark," American Journal of Infectious Diseases, vol. 5, no. 2, pp. 60-67, 2009.

[16] V. Gupta and S. Sharma, "Plants as natural antioxidants," Natural Product Radiance, vol. 5, no. 4, pp. 326-334, 2006.

[17] W. Goettsch, J. Garssen, F. R. De Gruijl, P. Dortant, and H. Van Loveren, "Methods for exposure of laboratory animals to ultraviolet radiation," Laboratory Animals, vol. 33, no. 1, pp. 58-67, 1999.

[18] S. K. Katiyar, F. Afaq, A. Perez, and H. Mukhtar, "Green tea polyphenol (-)-epigallocatechin-3-gallate treatment of human skin inhibits ultraviolet radiation-induced oxidative stress," Carcinogenesis, vol. 22, no. 2, pp. 287-294, 2001. 

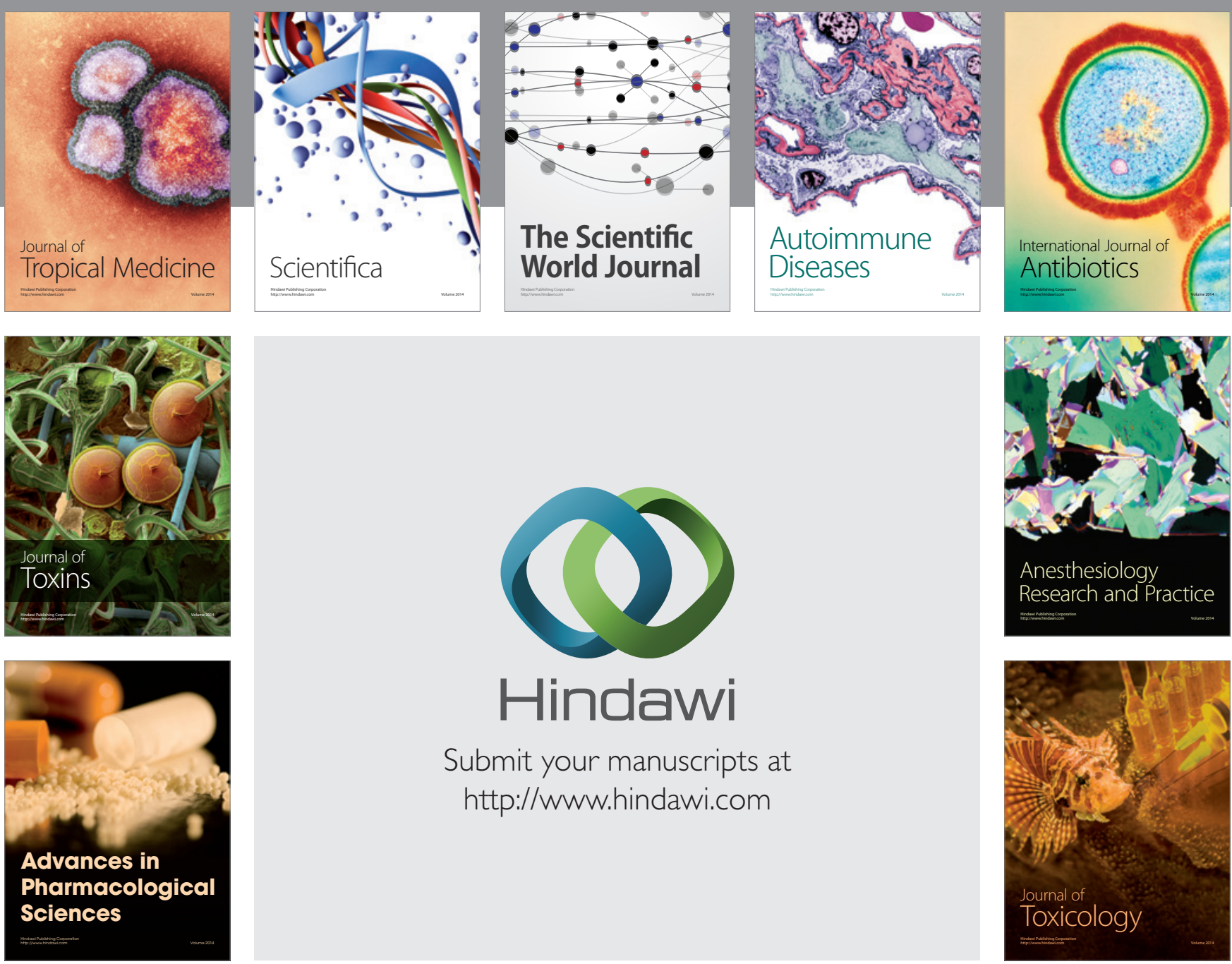

\section{Hindawi}

Submit your manuscripts at

http://www.hindawi.com
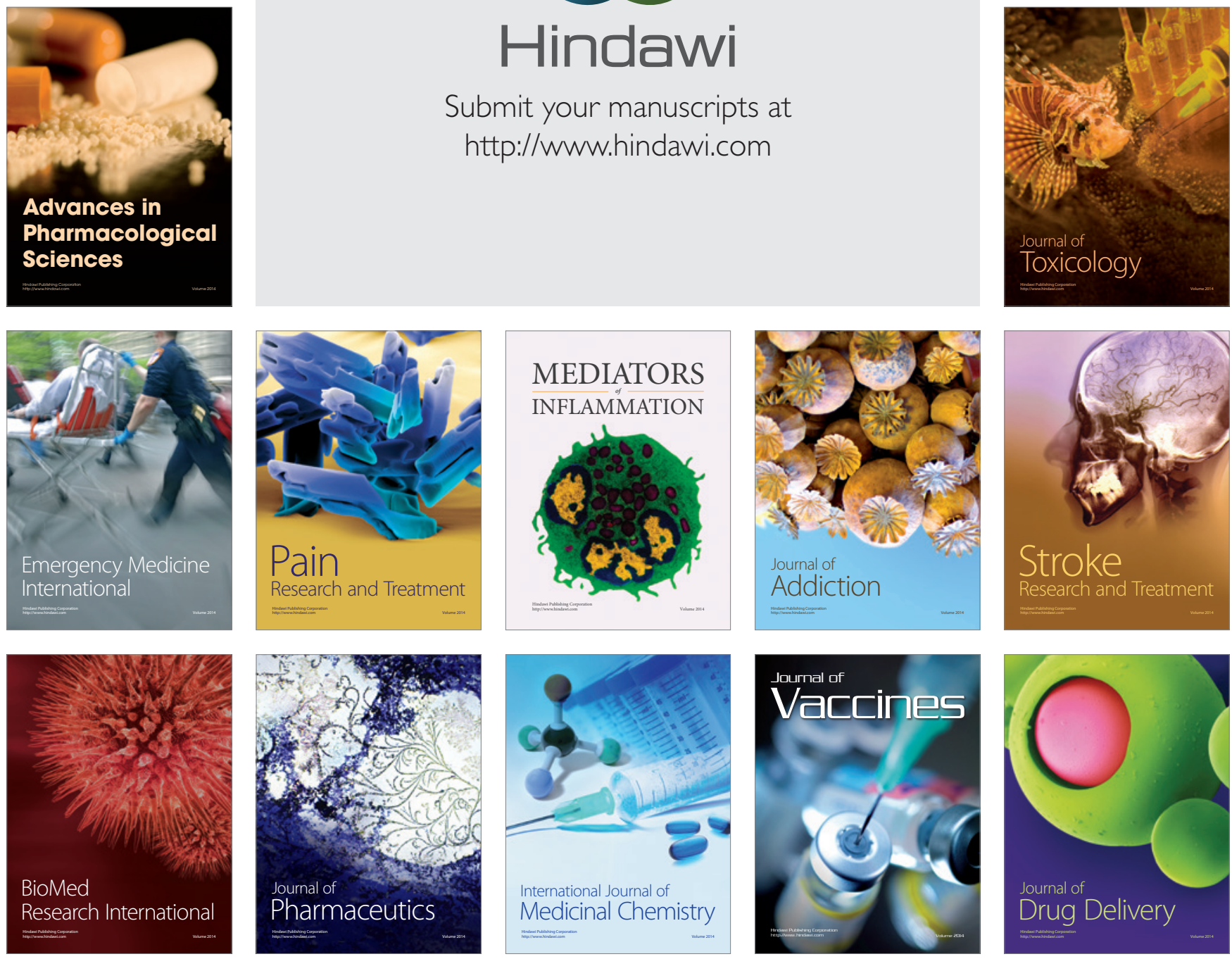